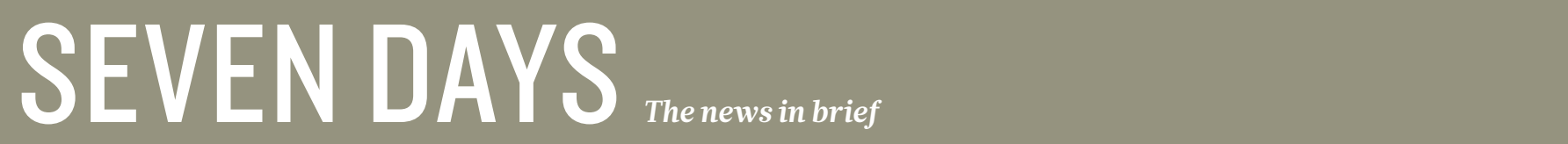

PEOPLE

\section{Astronaut minister}

Astronaut Pedro Duque was appointed Spain's minister of science, innovation and universities on 7 June. The country's socialist party formed a new minority government after a vote of no confidence ousted the previous prime minister. Spain's government science budget plunged by more than $30 \%$ after the 2008 financial crisis, and scientists say that austerity measures have added bureaucracy around research expenses. The government has committed to sticking with an austerity budget for 2018, but Duque says that he will try to ease some cost-controlling rules that delay laboratory purchases and the spending of grants. Duque was Spain's first astronaut, with the European Space Agency. He flew on the space shuttle Discovery in 1998 and to the International Space Station in 2003, where he ran science experiments.

\section{US science envoys}

A former astronaut is among five science envoys announced by the US Department of State on 8 June. In a programme begun under former US president Barack Obama, the envoys travel the world to strengthen international cooperation in science and technology. The new class comprises former NASA chief Charles Bolden, who flew aboard four space-shuttle missions; Robert Langer, a chemical engineer at the Massachusetts Institute of Technology in Cambridge; Michael Osterholm, an infectious-disease researcher at the University of Minnesota in Minneapolis; Rebecca Richards-Kortum, a bioengineer at Rice University in Houston, Texas; and James Schauer, who studies air quality at the University of

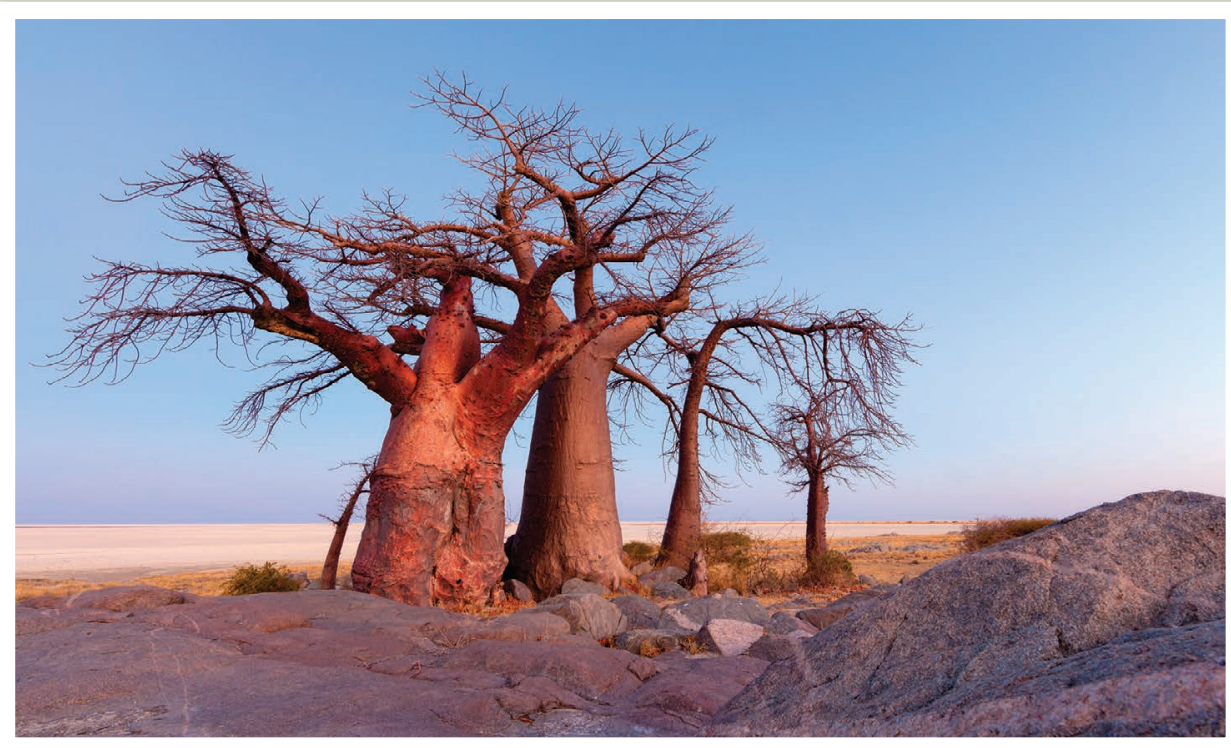

\section{Africa's iconic baobab trees are dying}

The oldest and largest baobab trees in Africa are dying - but no one knows why. The iconic African baobab tree (Adansonia digitata), which sports a wide trunk and high branches, is Earth's oldest living flowering plant, and it can live for 2,000 years. In a study intended to investigate the age, structure and longevity of Africa's largest and potentially oldest baobabs, researchers were surprised to find that several of the trees died during the study period. Between 2005 and 2017, they dated more than 60 trees and found that during that period, 9 of the oldest 13 trees died, as did 5 of the 6 largest ones. The researchers, who published their findings on 11 June, found no signs of an epidemic or disease; they suggest that changes in climate could be to blame (A. Patrut et al. Nature Plants http://doi.org/cqsh; 2018).
Wisconsin-Madison. Such appointments are rare for the administration of current US President Donald Trump, which has appointed very few science advisers.

\section{Verma resigns}

Cancer researcher Inder Verma has resigned from the Salk Institute for Biological Sciences in La Jolla, California, the institute said on 11 June. Verma had been temporarily suspended since 21 April, after several female scientists with ties to the institute alleged that he had sexually harassed and discriminated against them. The Salk Institute then began an investigation of the complaints, which Verma has repeatedly denied, and on
11 June its board of trustees met to discuss the findings of that probe. According to the institute, Verma resigned before the Salk board of trustees had concluded its investigation. At press time, Verma had not responded to Nature's request for comment.

\section{FUNDING}

\section{Private money}

US research institutions received more than US $\$ 2.3$ billion for basic science from philanthropic organizations and corporations in 2017 , according to a survey by the Science Philanthropy Alliance in Palo Alto, California. Now in its third year, the survey looked at 46 institutions and showed that private funding for basic science remained flat from 2016 to 2017. Among the 25 institutions for which the alliance has data from all three years, however, funding rose to $\$ 1.7$ billion in 2017 , a $13 \%$ increase from 2016 and a $40 \%$ increase from the $\$ 1.2$ billion that the survey registered in 2015.

\section{Hawking fellows}

The United Kingdom has established a postdoctoral fellowship scheme in honour of the late physicist Stephen Hawking. Over the next five years, national science funder UK Research and Innovation will award up to ten grants each year for 
$\succsim$ exceptional graduate students

喆 in mathematics, physics

妾 and computer science. The

funding, details of which are

yet to be released, will allow

ㅇ the students to continue the work from their doctorates at any institution in the country for up to three years. Science minister Sam Gyimah said that the fellowships offer a "fitting tribute" to Hawking, who died in March and whose work changed our understanding of the Universe.

\section{RESEARCH}

\section{Record flooding}

High-tide flooding in US coastal areas is twice as frequent as it was 30 years ago, according to a report released by the National Oceanic and Atmospheric Administration on 6 June. Tide gauges at 98 locations around the country (excluding Alaska) measured a record-high average of 6 flood days between May 2017 and April 2018. Sabine Pass, Texas, recorded the highest number of flood days, at 23. Although some of the flooding coincided with storms, much of it was a result of sea-level rise.

\section{POLICY}

\section{European science}

The European Commission has outlined how it plans to spend the biggest research and innovation budget in its history. On 7 June,

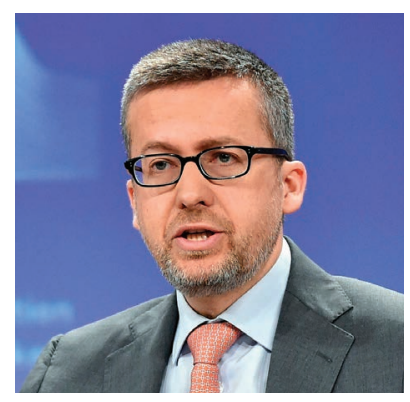

Carlos Moedas, the European Union's commissioner for research (pictured), presented a detailed proposal for the structure of the Horizon Europe science-funding programme, which will run from 2021 to 2027 and has a provisional budget of nearly $€ 100$ billion (US $\$ 117$ billion). Horizon Europe will have three main pillars: one each serving basic research and innovation, and another directed at solving societal challenges and at boosting industrial competitiveness. The programme will be open to all countries worldwide for the first time, giving the United Kingdom an opportunity to take part after Brexit. See go.nature. com/2llw3jf for more.

\section{Wild horses spared}

Science and environment groups in Australia have slammed new laws that will protect wild horses in New South Wales' largest national park. State politicians passed legislation to protect the heritage value of the horse an invasive species known as a brumby - on 6 June. It rules out a cull recommended by the state government's own environment department to reduce the number of horses to preserve delicate ecosystems in the Kosciuszko National Park.

The Australian Academy of Science says that the laws go against scientific advice, while the International Union for Conservation of Nature warns that the bill sets a disturbing precedent. Its passing prompted ecologist David Watson - a member of the state government's scientific advisory committee on threatened species - to resign in protest.

\section{EVENTS}

\section{Biotech start-up}

A non-profit institute launched by the Bill \& Melinda Gates Foundation earlier this year got its official introduction in a 7 June announcement at the BIO convention in Boston, Massachusetts. The Bill \& Melinda Gates Medical Research Institute, which will have offices in both Boston and Seattle, Washington, will focus on diseases of poverty in lowand middle-income countries. With US\$273 million for its first four years, the group's researchers will probe findings from early-stage studies conducted at universities and biotechnology companies in

\section{TREND WATCH}

About $70 \%$ of people in the United States think it is essential that their country remains a world leader in space exploration, a national survey of 2,541 people finds. And, in a time when the private space sector is growing, $65 \%$ say that NASA should still play a key part in space discovery. Respondents said that NASA's top priority should be monitoring Earth's climate system. But the idea of sending astronauts to the Moon or Mars - two priorities of Donald Trump's administration — didn't prove popular.

\section{WHAT SHOULD NASA DO?}

In a survey of 2,541 US adults, most identified climate monitoring as a top priority for NASA.

\section{Top priority Important but lower priority}

Not too important or should not be done

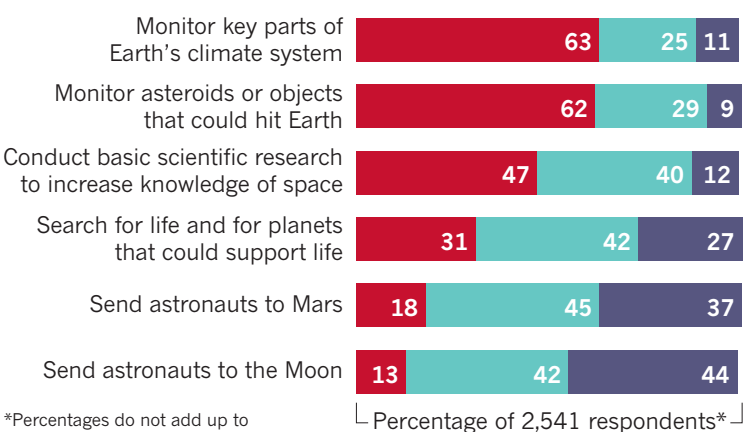

search of promising leads on cures for tuberculosis, malaria and diarrhoea - and aim to develop them until they are ready for clinical trials. The institute will then pass them to companies in return for commitments to make the products available to those in need.

\section{Malaria progress}

Paraguay is malaria-free, the World Health Organization (WHO) said on 11 June. The South American country hasn't had a single case of malaria in the past six years. The WHO reported the news in an update on 21 countries that are aiming to eliminate the disease by 2020 . The report highlights progress in China, El Salvador and Algeria, which each had fewer than ten cases last year. But South Africa, Botswana and several other countries hoping to eliminate the disease have instead seen a rise in cases. Resurgences are often caused by gaps in health care and lapses in mosquito control.

\section{SPACE}

\section{Space missions}

On 6 June, India’s government gave its space agency approval to help Oman build a space programme. A memorandum of understanding, signed by the two nations in February, calls for cooperation in space science, planetary exploration, satellite-based navigation and remote sensing of Earth. Oman joins a growing number of countries developing space programmes. The neighbouring United Arab Emirates announced last week that it has decided on a shortlist for its astronauttraining initiative. The list of 95 men and women will be reduced by the end of the year to 4 astronauts, who will participate in international space missions from 2021. The country is also planning an uncrewed mission to Mars in 2020 .

\section{ONATURE.COM}

For daily news updates see:

www.nature.com/news 